\title{
Lactobionic Acid Conjugated Quercetin Loaded Organically Modified Silica Nanoparticles Mitigates Cyclophosphamide Induced Hepatocytotoxicity
}

This article was published in the following Dove Press journal: International Journal of Nanomedicine

\author{
Saba Naqvi (iD) \\ Harish Sharma \\ Swaran JS Flora iD \\ Department of Pharmacology \& \\ Toxicology, National Institute of \\ Pharmaceutical Education and Research \\ (NIPER-Raebareli), Lucknow 226002, \\ India
}

Objective: The study was designed to investigate the therapeutic potential of lactobionic acid (LA) conjugated quercetin (Q) loaded organically modified silica nanoparticles (LA-QORMOSIL) with bulk quercetin to mitigate cyclophosphamide (CP) induced liver injury.

Methodology: Q-ORMOSIL nanoparticles were synthesized and characterized using UV-Vis spectroscopy, TEM, Zeta sizer, FTIR and EDX. Further, encapsulation efficiency and in vitro release kinetic study was done. Q-ORMOSIL nanoparticles surface were modified with lactobionic acid, a ligand for the asialoglycoprotein receptor on the hepatocyte surface. The hepatoprotective effects of Q-ORMOSIL and LA-Q-ORMOSIL nanoparticles were evaluated in vivo. Cyclophosphamide $(20 \mathrm{mg} / \mathrm{kg} / \mathrm{day}$, i.p) was co-administered for seven days with bulk quercetin $(50 \mathrm{mg} / \mathrm{kg} /$ day) and quercetin nanoparticles $(50 \mu \mathrm{g} / \mathrm{kg} /$ day $)$. After seven days, the number of biomarkers for liver function test and oxidative stress were determined in liver homogenate. Histopathological changes were also analyzed in control and treated liver tissues. Results: Physiochemical characterization of LA-Q-ORMOSIL nanoparticles depicts that the particles formed were of approx. $80 \mathrm{~nm}$, spherical, monodispersed in nature and showed sustain drug release in in vitro study. Our results further suggested that Q-ORMOSIL and LA-QORMOSIL nanoparticles significantly decreased tissue TBARS, ROS levels and ALT, AST, and ALP activities compared to CP induced group. On the other hand, tissue antioxidant levels (GSH, GST, and catalase) showed a significant increase in LA-Q-ORMOSIL treated group compared to the CP treated group confirming its high therapeutic efficacy during liver injury.

Conclusion: Targeted nanoquercetin demonstrated a significant hepatoprotective effect compared to bulk quercetin against CP-induced hepatotoxicity and it considerably reduced bulk quercetin dose level to many folds. Bulk quercetin has low bioavailability and thus, from obtained data we suggest that LA-Q-ORMOSIL nanoparticles provide high therapeutic value in protecting experimental animals against $\mathrm{CP}$-induced liver injury. We also propose multifunctional dye-doped LA-modified ORMOSIL nanoparticles for future studies in facilitating nanoparticles uptake to hepatocytes for liver diagnosis and treatment.

Keywords: quercetin, ORMOSIL nanoparticles, cyclophosphamide, hepatoprotection, lactobionic acid

\section{Introduction}

Cyclophosphamide(CP) is well known for its wide spectrum of clinical implication like anticancer and immunosuppressive activities. ${ }^{1}$ Despite its therapeutic value, its uses are often limited for the reason that it exhibits a number of toxic effects like hepatotoxicity, and nephrotoxicity, etc. ${ }^{2}$ The mechanism behind the hepatotoxic effects are not fully understood but cytotoxic effects are attributed due to its 
metabolic products. Cyclophosphamide metabolizes hepatic cytochrome P450 enzymes, which yields phosphoramide mustard and acrolein. ${ }^{3}$ Phosphoramide mustard moiety is responsible for its therapeutic action considering its anticancerous effects but acrolein moiety is toxic. Acrolein gets metabolized further by glutathione sulfhydryl groups, forming mercapturic acid that is eliminated in urine. This mechanism is directly associated with the increase of cellular oxidative stress and the generation of ROS by decreasing glutathione level. ${ }^{4}$ Aldehyde dehydrogenase also metabolizes acrolein and generate $\mathrm{O}_{2}{ }^{-}$radicals which play an important role in the induction of lipid peroxidation. ${ }^{5}$ It has been reported that cyclophosphamide exposure results in increased oxidative stress and generates biochemical changes. Overproduction of oxidative stress and free radicals results in the damage to liver cells that might further be leading to cell death. Various naturally obtained moieties including liquiritigenin, ${ }^{6}$ silymarin $^{7}$ arjunolic acid ${ }^{8}$ and dioscin ${ }^{9}$ shown to possess hepatoprotective effects. Similarly, quercetin is also a naturally obtained moiety and has both antioxidant as well as anti-inflammatory properties. Quercetin (3,5,7,3,4-pentahydroxyflavone), is a flavonoids and is found mainly in vegetables, fruits, tea, olive oil, and other dietary sources. ${ }^{10}$ The therapeutic effect of quercetin has earlier been reported where quercetin protects oxidative stress against UV light, ${ }^{11}$ hinders angiogenesis and carcinogenesis. ${ }^{12,13}$ Quercetin act as a scavenger of reactive oxygen species and inhibits lipid peroxidation. ${ }^{14}$ It has been reported that the treatment with quercetin significantly decreases liver enzymes in chloroform-induced liver injury in rats, thus supporting the argument that quercetin has both antioxidant and hepatoprotective effects. ${ }^{15}$ It has been reported that $20 \%$ of orally administered quercetin was absorbed in rats ${ }^{16,17}$ and over $90 \%$ of intraperitoneally administered quercetin was metabolized after one hour. ${ }^{18}$ Rapid metabolism, low solubility, and less bioavailability are the major shortcomings associated with the quercetin. Thus, a novel drug delivery system might be an effective strategy with target specificity to improve its bioavailability and therapeutic efficacy.

Nanotechnology opens new opportunities for the administration of drugs. Advancement in the nanomedicine helps to develop a carrier system which can deliver drugs to the target sites by targeting specific moiety on the cell surface. Various nanoparticles like inorganic nanoparticle, liposomal, polymeric, albumin and others nanoparticles have been developed to deliver drugs to a specific site. Among various types of nanoparticle, silica nanoparticles are versatile in nature due to its inert property and also act as a good carrier for biological materials like enzymes and genetic material. It provides numerous sites for different molecules to attach on its surface like amino thiol, hydroxyl, and carboxyl groups for targeting specific delivery of drugs. ${ }^{19}$ Lactobionic acid (LA) is an aldonic acid classified as oligosaccharide. Upon enzymatic hydrolysis it breakdowns into galactose and gluconic acid. Lactobionic acid serves as targeted moiety and ligand for the asialoglycoprotein receptor (ASGPRs), which are widely present on the surface of hepatocytes. This receptor shows a high affinity towards galactose containing moiety helpful in targeted drug delivery. ${ }^{20}$

In the present study, organically modified silica (ORMOSIL) nanoparticles were used to encapsulate quercetin and further lactobionic acid immobilized by chemical conjugation on nanoparticle's surface for the targeted drug delivery to the hepatocytes. Thus, we hypothesized that lactobionic acid conjugated quercetin loaded ORMOSIL nanoparticles may increase quercetin solubility, improves its bioavailability and may be useful in the treatment against cyclophosphamideinduced hepatotoxicity.

\section{Materials And Methods Materials}

Quercetin(Q),triethoxyvinylsilane(TEVS),3-aminopropyl triethoxysilane(APTES), lactobionic acid (LA), N-hydr oxysuccinimide(NHS), 1-ethyl-3-(3-dimethylaminopropyl) carbodiimide (EDC) were purchased from Sigma Aldrich Chemicals (USA), n-butanol, Tween 80 from Loba Chemie and all other reagents used were of high purity and analytical grade.

\section{Methods}

\section{Synthesis Of Quercetin Loaded ORMOSIL} Nanoparticles (Q-ORMOSIL)

Q-ORMOSIL nanoparticles were synthesized by a reported nanomicelles method with some minor modification. ${ }^{21}$ Nanoparticles were synthesized using the nonpolar core of Tween80/1-butanol/water micelles. In brief, ORMOSIL nanoparticles were prepared by taking $20 \mathrm{~mL}$ of doubledistilled water and $404 \mu 1$ of tween 80 and $800 \mu 1$ of n-butanol dissolved in it with magnetic stirring at $600 \mathrm{rpm}$ for $5 \mathrm{~min}$. Quercetin was dissolved in dimethylformamide (DMF) and $60 \mu \mathrm{l}$ was added into the above mixture with constant magnetic stirring at $600 \mathrm{rpm}$ until a clear solution 
was obtained. In case of the void nanoparticle, $60 \mu \mathrm{L}$ of DMF only, was added in place of quercetin. $200 \mu \mathrm{L}$ of triethoxyvinylsilane was added to the above solution and stirred for $1 \mathrm{hr}$ until the solution became clear. Lastly, $10 \mu \mathrm{L}$ of 3-aminopropyltriethoxysilane was added into the system and stirred for $48 \mathrm{hrs}$ using magnetic stirrer. The entire reaction was performed at the room temperature. The formed nanoparticles were dialyzed with a dialysis membrane (12 kDa cut off, Sigma) for 2 days to remove free unreacted molecules from the reaction mixture. The final product was lyophilized and stored at $4^{\circ} \mathrm{C}$ for further use.

\section{Surface Modification Of Q-ORMOSIL}

Surface modification was done using a reported method with minor modification. ${ }^{22}$ In brief, lactobionic acid (2.1mM, 752.43mg), EDC $(2.1 \mathrm{mM}, 402.54 \mathrm{mg})$, NHS $(2.1 \mathrm{mM}, 241.5 \mathrm{mg})$ were taken in equal molar equivalents concentration and dissolved in $10 \mathrm{~mL}, 0.02 \mathrm{mM}$ phosphate buffer (pH 6.0) with magnetic stirring for $3 \mathrm{hrs}$. After $3 \mathrm{hrs,}$ lactobionic acid (LA) gets activated and used for further modification. Then equimolar equivalent of Q-ORMOSIL was taken and activated LA was slowly added in a dropwise manner with vigorous stirring. The whole solution was slowly stirred for 3 days at the room temperature. The formed nanoparticles were dialyzed with a dialysis membrane (12 kDa cut off, Sigma) for 2 days to remove free unreacted molecules from the reaction mixture. The final product was lyophilized and stored at $4^{\circ} \mathrm{C}$ for further use.

\section{Physical Characterization Of Nanoparticles UV-Visible Spectrophotometry}

UV-Visible spectrophotometry was performed to obtain a characteristic absorption peak of quercetin and synthesized nanoparticles over a range of 200 to $800 \mathrm{~nm}$ using UV $3000^{+}$spectrophotometer (LabIndia, Mumbai, India).

\section{Fourier Transform Infrared (FTIR) Spectroscopy Measurements}

FTIR was performed to determine the functional groups present in the synthesized nanoparticles. FTIR spectra of quercetin, Q-ORMOSIL, and void ORMOSIL nanoparticles were obtained (ALPHA, BRUKER, Germany). Briefly, samples and $\mathrm{KBr}$ were mixed and compressed into thin pellets. The scanning range was $500-4000 \mathrm{~cm}^{-1}$ with resolution $\mathrm{cm}^{-1}$. Each sample were measured and recorded in triplicate.

\section{Particle Size Distribution}

The average particle size and size distribution of the synthesized nanoparticles were determined using Nanosize 90ZS (Malvern instrument, UK) at CSIRCentral Drug Research Institute (CSIR-CDRI), Lucknow, India. The measurements were carried out using disposable cuvette and keeping the temperature at $25^{\circ} \mathrm{C}$ throughout the experiment. Prepared nanoparticles were diluted with triple distilled water and measured using a Zetasizer.

\section{Transmission Electron Microscopy (TEM) And Energy Dispersive X-ray (EDX) Analysis}

Size and morphology of the synthesized nanoparticles were examined using TEM (JEOL JEM 1400, JEOL Ltd, Japan) at CSIR-CDRI, Lucknow. One drop of quercetin loaded ORMOSIL nanoparticle were put on the carbon-coated copper grid and an excess amount of sample was removed carefully followed by negative staining using $2 \%$ phosphotungstic acid, air-dried the samples for some time and viewed under the transmission electron microscope. EDX (energy-dispersive X-ray) (JEOL, Japan). Studies were carried out to know the elemental composition ORMOSIL nanoparticles.

\section{X-ray Diffraction (XRD) Analysis}

XRD analysis of synthesized ORMOSIL nanoparticles was done in XRD with, $\mathrm{Cu} \mathrm{K} \alpha$ radiation $(\lambda=1.54 \mathrm{~nm})$ in the $2 \theta$ range of $20-80$ operate data voltage of $40 \mathrm{kV}$ and a current of $30 \mathrm{~mA}$.

\section{Entrapment Efficiency (E\%)}

The entrapment efficiency of the quercetin loaded in the nanoparticle was determined. To determine entrapment efficiency, synthesized nanoparticles were separated using a NANOSEP (100 kD cut-off) membrane filter to remove free quercetin from the solution, and the amount of free quercetin was measured spectrophotometrically at $402 \mathrm{~nm}$. The entrapment efficiency was calculated as follows:

Entrapment Efficiency $(\mathrm{E} \%)=\left(\begin{array}{l}\text { Quercetin }_{\text {Total }} \\ - \text { Quercetin }_{\text {free/ }} \\ \text { Quercetin }_{\text {Total }}\end{array}\right) \times 100$

Where quercetin ${ }_{\text {Total }}$ is the initial amount of quercetin loaded in nanoparticles, and quercetin $n_{\text {Free }}$ is the amount of unentrapped quercetin in the solution.

\section{In Vitro Release Study}

Synthesized nanoparticles were transferred into the membrane dialysis bag (12 kD cut off). Dialysis bag was then placed in the beaker containing phosphate buffer ( $\mathrm{pH}$ 7.4) maintained at $37^{\circ} \mathrm{C}$ with constant stirring at $100 \mathrm{rpm}$. After 
a definite time interval, it was centrifuged at $3000 \mathrm{rpm}$ for $10 \mathrm{~min}$. The released quercetin was separated and redispersed in $1 \mathrm{~mL}$ of DMF and the absorbance was measured spectrophotometrically at $402 \mathrm{~nm}$. Average values were taken and the cumulative percentage of drug release was calculated and plotted against time.

\section{In Vivo Study}

\section{Animals}

Male Wistar rats weighing 180-200 g were procured from the animal facility of CSIR-CDRI, Lucknow, India. The rats were acclimatized for one week before the experiment in the departmental animal house at room temperature of $\left(25 \pm 2^{\circ} \mathrm{C}\right)$ with $12 \mathrm{hrs}$ light/dark cycles. Animal had free access to the standard chow pellet diet (Altromin,Germany) and tap water. The animals received humane care as per the guidelines of the Committee for the Purpose of Control and Supervision of Experiments on Animals (CPCSEA), Government of India, and prior permission was permitted from the Institutional Animal Ethics Committee of National Institute of Pharmaceutical Education and Research, Raebareli(Approval no. NIPER/RBL/IAEC/24/August2018)

\section{Experimental Procedure}

Animals were divided into five groups of 5 animals each and treated as below for 7 days -

Group 1 - Normal tap water (Control); (C)

Group 2 - Cyclophosphamide (20 mg/kg, Intraperitone ally); (CP)

Group 3 - Cyclophosphamide $(20 \mathrm{mg} / \mathrm{kg})$, + quercetin (50 mg/kg i.p.); (CP + Q):

Group 4 CP (20 mg/kg), + Q-ORMOSIL $(50 \mu \mathrm{g} / \mathrm{kg})$, (CP + Q-ORMOSIL):

Group 5 CP(20 mg/kg), LA-Q-ORMOSIL (50 $\mu \mathrm{g} / \mathrm{kg}$, i.p.). (CP + LA-Q-ORMOSIL):

Treatment drugs were administered 30 min after CP treatment.

At the end of the experiment, blood was collected by cardiac puncture and animals were sacrificed. Blood was collected in an anticoagulant containing tubes and plasma were separated by centrifugation at $4^{\circ} \mathrm{C}$ and used for the estimation of liver enzymes test and other biochemical estimation. The liver was surgically removed from the adhering connective tissues, washed in an isotonic solution $(0.9 \% \mathrm{NaCl})$ and stored at $-80^{\circ} \mathrm{C}$ until analysis until use. The liver tissues $(10 \% \mathrm{w} / \mathrm{v})$ were homogenized in ice-cold phosphate buffer ( $\mathrm{pH} 7.4$ ) using a homogenizer at $2000 \mathrm{~g}$. The tissue homogenates were then centrifuged at $10,000 \mathrm{~g}$ for 10 mins at $4^{\circ} \mathrm{C}$. The clear supernatant obtained was separated and used for the enzymatic assay.

\section{Biochemical Estimation}

Liver Function Test

Plasma aspartate transaminase (AST), alanine transaminase (ALT), and alkaline phosphatase (ALP) activities were determined using diagnostic kits on Biochemistry analyzer (Transasia Bio-Medical Ltd, Erba Mannheim, EM 200, Mumbai).

\section{Determination Of Proteins}

The protein concentration was determined by taking $200 \mu \mathrm{L}$ of liver homogenates. $1 \mathrm{~mL}$ of alkaline copper reagent [Reagent $\mathrm{C}=50 \mathrm{~mL}$ of Reagent $\mathrm{A}$ (2\% sodium carbonate in $0.1 \mathrm{~N} \mathrm{NaOH})+1 \mathrm{~mL}$ of Reagent $\mathrm{B}(0.5 \%$ copper sulphate in $1 \%$ sodium potassium tartrate)] were mixed. After addition of reagent $\mathrm{C}$, the mixture was incubated at the room temperature for $10 \mathrm{mins}$. $1 \mathrm{~mL}$ of Folin's ciocalteau phenol reagent was added and incubated in dark for $30 \mathrm{mins}$ at room temperature. Bovine serum albumin was used as the standard in the range of 10-640 $\mu \mathrm{g}$ which was also treated in the same manner as described above. The blue color developed was read at $660 \mathrm{~nm}^{23}$

\section{Reactive Oxygen Species (ROS) Assay}

This assay performed by the reported fluorometric method with some minor modification. $10 \mu \mathrm{l}$ of tissue supernatant was taken and treated with the $5 \mu \mathrm{L}$ of $5 \mu \mathrm{M}$ 2,7-dichlorofluorescein (DCFDA) with the addition of $885 \mu \mathrm{L}$ of distilled water. The mixture was incubated for $30 \mathrm{mins}$, to allow DCFDA to get converted into DCF and the fluorescence was measured at 485/525 $\mathrm{nm}$. The standard plot of dichlorofluorescein (DCF) was also prepared and treated similiarly as above. ${ }^{24}$

\section{Thiobarbituric Acid Reactive Substances (TBARS) Assay}

Lipid peroxide contents of the liver tissue samples were determined by TBARS assay by taking $100 \mu \mathrm{L}$ of supernatant. $750 \mu \mathrm{L}$ of $0.8 \%$ thiobarbituric acid, $100 \mu \mathrm{L}$ of $8.1 \%$ sodium dodecyl sulfate solution, $750 \mu \mathrm{L}$ of $20 \%$ acetic acid and $300 \mu \mathrm{l}$ of distilled water was mixed. The mixture was vortexed and kept in a boiling water bath for 60 mins. The tubes were cooled and centrifuged at 2000rpm for 10 mins. A pink colored complex formed in the supernatant was read at $535 \mathrm{~nm}$. $100 \mu \mathrm{M}$ tetra ethoxy propane solution used as standards in the range of 5-80 $\mu \mathrm{M}$ were treated in a similar manner. ${ }^{25}$ 


\section{Superoxide Dismutase}

To determine superoxide dismutase activity, $0.2 \mathrm{~mL}$ of supernatant was taken and $1.2 \mathrm{~mL}$ of sodium pyrophosphate $(0.052$ $\mathrm{M}, \mathrm{pH} 8.3), 0.3 \mathrm{~mL}$ phenazine methosulphate $(186 \mu \mathrm{M})$, $0.3 \mathrm{~mL}$ of nitro blue tetrazolium $(300 \mu \mathrm{M})$, nicotinamide adenine dinucleotide $(780 \mathrm{mM})$ and $0.2 \mathrm{~mL}$ of distilled water was mixed well. The mixture was vortexed and incubated at $30^{\circ} \mathrm{C}$ for 90 seconds. $1 \mathrm{~mL}$ of acetic acid was added within 90 seconds and the violet color developed was measured at the absorbance at $560 \mathrm{~nm}^{26}$

\section{Catalase Activity}

Briefly, the assay was performed by taking $1 \mathrm{~mL}$ of phhospate buffer $(0.01 \mathrm{M}, \mathrm{pH} 7.7), 100 \mu \mathrm{L}$ of the supernatant, $500 \mu \mathrm{l}$ distilled water and $500 \mathrm{ul}$ of $0.2 \mathrm{M} \mathrm{H}_{2} \mathrm{O}_{2}$. The mixture was vortexed properly and incubated for $1 \mathrm{~min}$ at $37^{\circ} \mathrm{C} .2 \mathrm{~mL}$ of $5 \%$ potassium dichromate and acetic acid in the ratio of 1:3 was added to stop the reaction. The entire whole mixture was kept on a boiling water bath for 10 mins and cooled to measure the absorbance at $570 \mathrm{~nm}$. $0.2 \mathrm{M}$ hydrogen peroxide $\left(\mathrm{H}_{2} \mathrm{O}_{2}\right)$ was used as a standard in the range of (2-64) $\mathrm{mM}$ by providing the same conditions. ${ }^{27}$

\section{Reduced Glutathione (GSH) Assay}

Reduced glutathione was determined using the fluorometric method. The liver homogenate was prepared by taking $250 \mathrm{mg}$ of liver tissue in $3.75 \mathrm{~mL}$ of phosphateEDTA buffer and $1 \mathrm{~mL}$ of $25 \% \mathrm{HPO}_{3}$ which was used for the precipitation of proteins. The mixture was centrifuged and $0.5 \mathrm{~mL}$ of supernatant was taken and mixed with $4.5 \mathrm{~mL}$ of phosphate buffer, $\mathrm{pH} 8.0 .100 \mu \mathrm{l}$ of this mixture was taken and mixed with $1.8 \mathrm{~mL}$ of buffer and $100 \mu \mathrm{l}$ of o-Phthal-aldehyde solution (prepared in absolute methanol). It was mixed properly and incubated at room temperature for $15 \mathrm{~min}$ and the fluorescence was determined at the emission $420 \mathrm{~nm}$ and excitation $350 \mathrm{~nm} .^{28}$

\section{Glutathione-S-Transferase (GST) Activity}

For GST activity, the stock solution of 1-Chloro-2,4-dinitrobenzene CDNB was prepared in acetone $(3 \mathrm{mg} / \mathrm{mL})$ and then further dilutions were done to obtain the required concentration $(1 \mathrm{mM})$. The required concentration of glutathione was prepared $(0.3 \mathrm{mg} \mathrm{GSH} / \mathrm{mL}$ in 0.2M phosphate buffer, $\mathrm{pH}=7.4$ ). $20 \mu \mathrm{l} \mathrm{CDNB}, 2.9 \mathrm{~mL}$ of GSH were taken in a test tube and mixed with $30 \mu 1$ of tissue supernatant. While $30 \mu \mathrm{L}$ distilled water was added in the blank test tube. Absorbance was taken using UV visible spectrophotometer at 30 seconds interval for 3 mins at $340 \mathrm{~nm}^{29}$

\section{Histopathology}

The rats were sacrificed, and liver tissues were preserved in $4 \%(\mathrm{v} / \mathrm{v})$ formaldehyde. The livers were processed and embedded in paraffin wax and $7 \mu \mathrm{m}$ thick sections were cut using precision rotary microtome (York scientific Industries Pvt. Ltd., India). These sections were processed and mounted on slides, stained with hematoxylin and eosin and examined under an inverted phase-contrast microscope (DMi1,Leica).

\section{Statistical Analysis}

Results were presented as mean $\pm \mathrm{SD}$. The data were compared by one-way analysis of variance (ANOVA) followed by Bonferroni's test for comparison of multiple groups. $p$-values less than 0.05 was considered significant. All calculations were performed using graph pad PRISM ${ }^{\text {TM }}$ 6 software.

\section{Results}

\section{Physicochemical Characterization UV-Visible Spectrophotometry}

The spectrum obtained displayed a characteristic peak at $402 \mathrm{~nm}$ for quercetin alone and quercetin loaded ORMOSIL NPs as shown in Figure 2. Further, void nanoparticles do not show any absorption spectrum at $402 \mathrm{~nm}$ which is the characteristic peak of quercetin. Synthesis of ORMOSIL nanoparticles was done as reported where a transparent solution of nanomicelles was turned into the yellowish-orange color when drug combined with the 3APTES (Figure 2), whereas due to the absence of drug white opaque color solution obtained in case of void nanoparticles.

\section{Fourier Transform Infrared (FTIR) Spectroscopy Measurements}

FT-IR spectroscopy was performed to determine the presence of surface and functional groups and the interaction of the functional group with drug moiety. Surface modification of Q-ORMOSIL with LA confirmed by FTIR. Figure 3 displayed spectra of quercetin, Q-ORMOSIL, and LA-Q-ORMOSIL. Characteristic peaks of quercetin were detected where $\mathrm{O}-\mathrm{H}$ stretching was detected at 3375 and $3294 \mathrm{~cm}^{-1}$, phenolic $\mathrm{O}-\mathrm{H}$ bending confirmed at $1362 \mathrm{~cm}^{-1}$. The peak at $2928 \mathrm{~cm}^{-1}$ represents $\mathrm{C}-\mathrm{H}$ stretch. Aryl ketonic stretch $\mathrm{C}=\mathrm{O}$ at $1660 \mathrm{~cm}^{-1}$. Peaks at $1609,1559,1513 \mathrm{~cm}^{-1}$ correspond to $\mathrm{C}=\mathrm{C}$ aromatic 

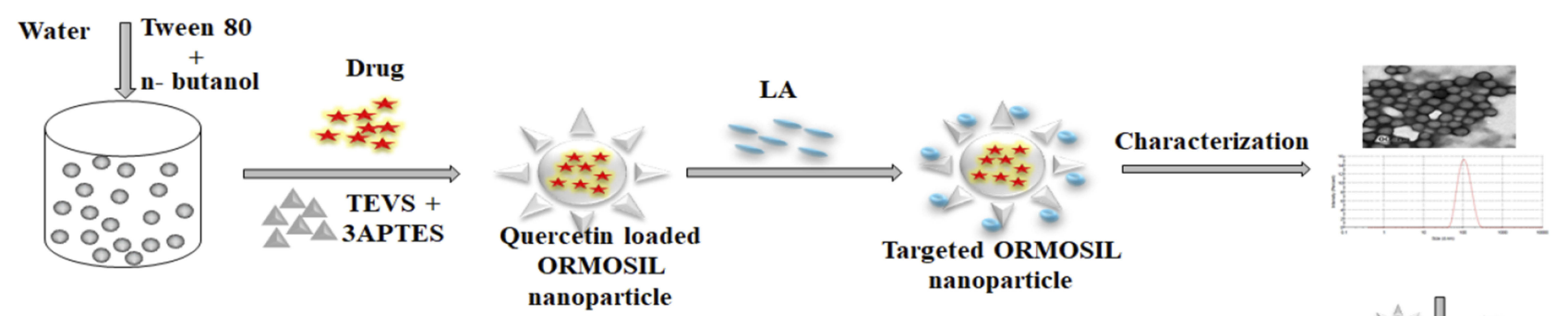

ORMOSIL
nanoparticle

TEVS - Triethoxyvinylsilane

3APTES -3 aminopropyltriethoxysilane

LA - Lactobionic acid

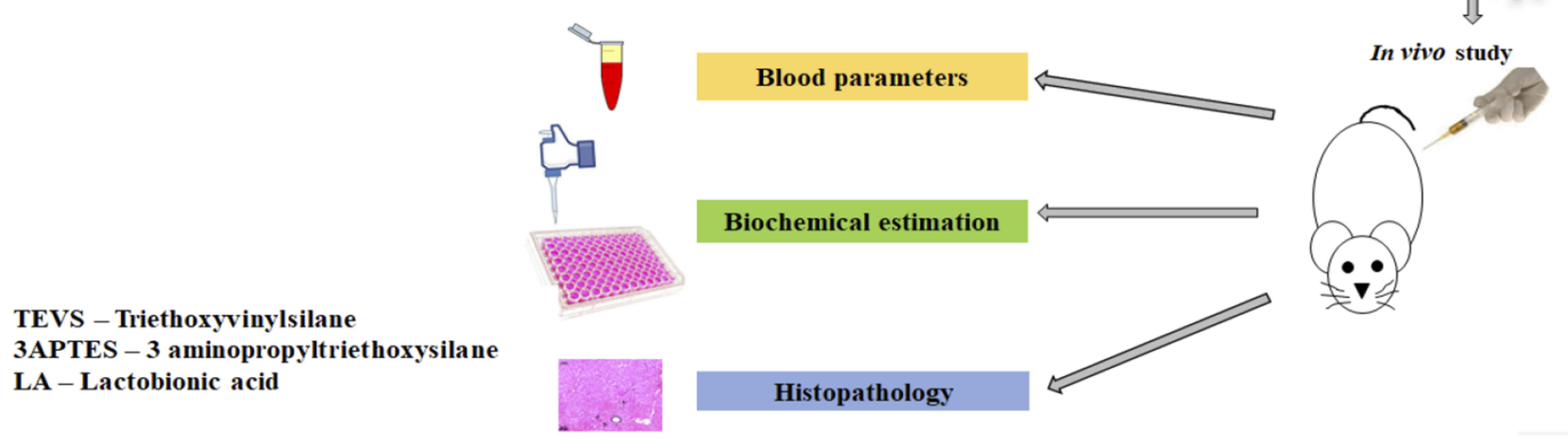

nanoparticle

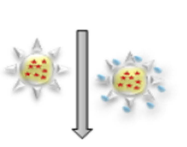

Figure I Schematic presentation of nanoparticle preparation, its characterization and in vivo study.

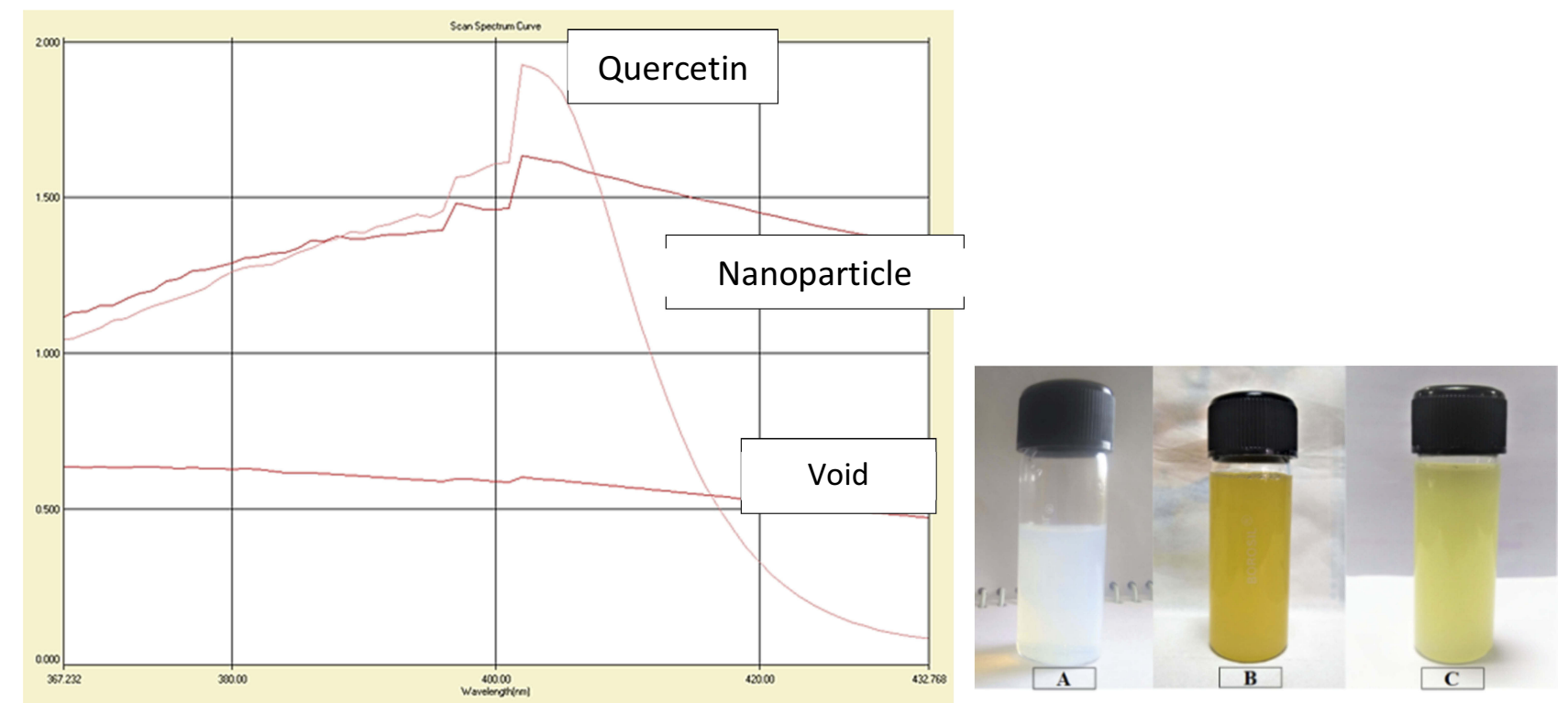

Figure 2 (Left) UV-Visible spectrophotometric data of quercetin, void and nanoparticles. (Right) Images of synthesized nanoparticles (A) Void nanoparticles, (B) Q-ORMOSIL and (C) LA-Q-ORMOSIL.

ring stretch, also $\mathrm{C}-\mathrm{H}$ bands were detected at 1312, 931, $801,706 \mathrm{~cm}^{-1}$. Peaks which were detected at 1243,1204 , $1161 \mathrm{~cm}^{-1}$ were attributed to $\mathrm{C}-\mathrm{O}$ stretching in aryl ether ring, $\mathrm{C}-0$ stretching in phenol ring and $\mathrm{C}-\mathrm{CO}-\mathrm{C}$ stretch and bending in ketone, respectively. Whereas, peaks at $1068 \mathrm{~cm}^{-1}$ and $1115 \mathrm{~cm}^{-1}$ correspond to vibrations of the Si-O-Si group, indicating that the sample is mainly composed of an inorganic-silica network. The band situated at
$1636 \mathrm{~cm}^{-1}$ are attributed to bending absorption of the $\mathrm{O}-\mathrm{H}$ groups, respectively. The vibration of $\mathrm{Si}-\mathrm{OH}$ causes the absorption observed around $900 \mathrm{~cm}^{-1}$. Absorption at $2953 \mathrm{~cm}^{-1}$ confirms the presence of $\mathrm{C}-\mathrm{NH}_{2}$ stretch vibration. The reaction between ORMOSIL and LA showed some absorption which was detected at $3284 \mathrm{~cm}^{-1}$ with increased absorption and $1636 \mathrm{~cm}^{-1}$ having high intensity, represents $\mathrm{NH}_{2}$ vibration and $\mathrm{N}-\mathrm{H}$ bond formation. 


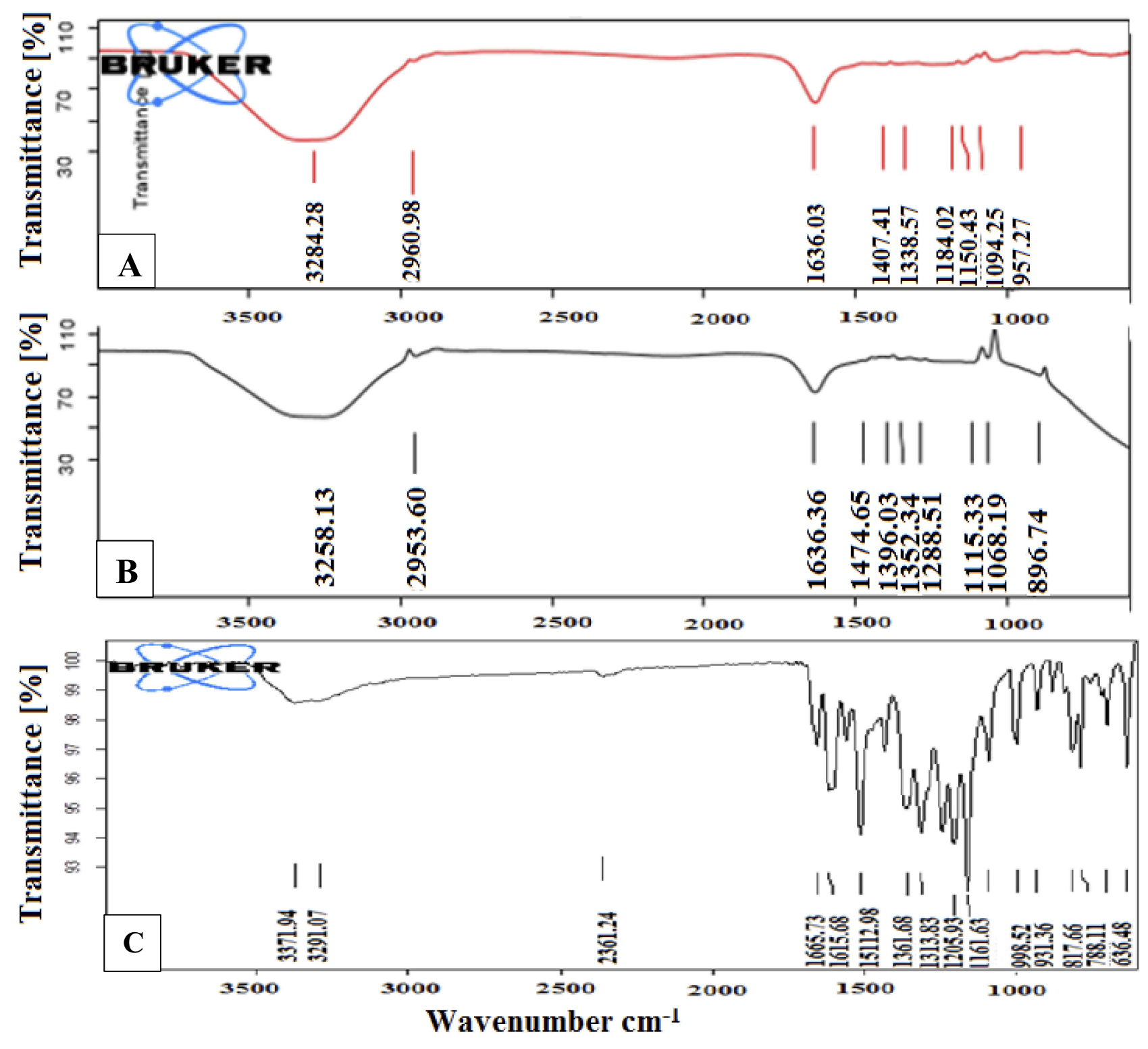

Figure 3 The Fourier transform infrared spectroscopy of (A) LA-Q-ORMOSIL (B) Q-ORMOSIL and (C) quercetin.

\section{Transmission Electron Microscopy (TEM) Measurement And EDX Analysis}

Figure 4A shows the TEM picture of quercetin loaded ORMOSIL nanoparticle. The average size was found around $80 \mathrm{~nm}$, with spherical morphology. Figure $4 \mathrm{C}$ represents the elemental analysis of the silica nanoparticles using Energy Dispersive Spectrum (EDX) on the SEM analysis, showing the peak of silica in their spectrum. Silica has the $14 \%$ weight percentage while the rest of the peaks of the EDS spectrum correspond to the other $(\mathrm{C}$ and $\mathrm{O})$ elements.

\section{Particle Size Distribution}

Figure 4B shows the particle size distribution for quercetin loaded nanoparticles. The average size was found to be $103.5 \mathrm{~nm}$.

The XRD pattern of quercetin nanoparticles was obtained to check the crystalline characteristic of quercetin nanoparticles. Figure 5 exhibits characteristic peaks of Q-ORMOSIL nanoparticles exhibited at a diffraction angle of $2 \Theta=24.6^{\circ} \theta$ and $27.4 \theta$ can be inferred to traits of high crystalline structure. 

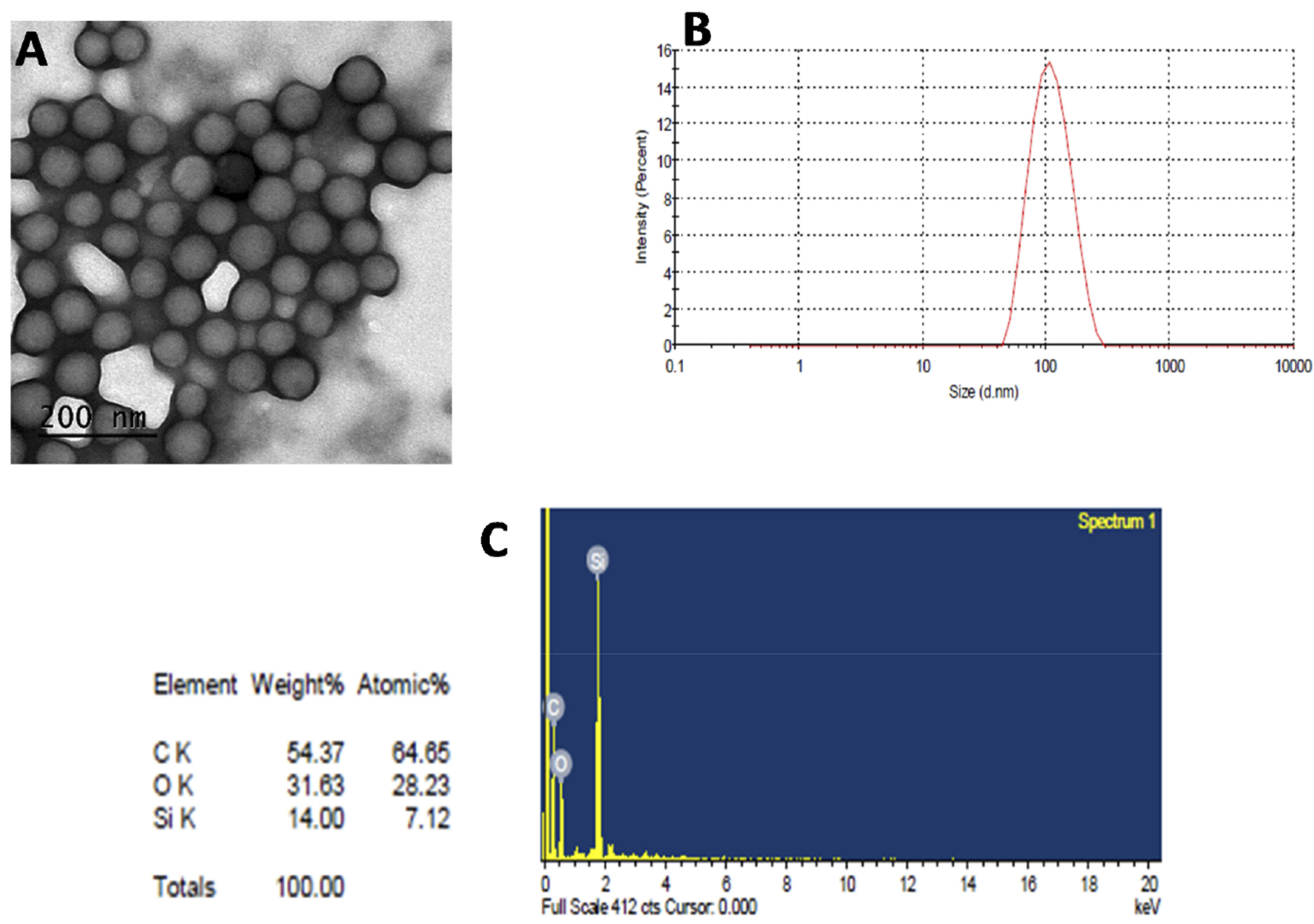

Inca

Figure 4 (A) Shows transmission electron microscopy analysis of nanoparticles, (B) represents size distribution of nanoparticles, (C) represents EDX analysis. Powder $X$ ray diffraction.

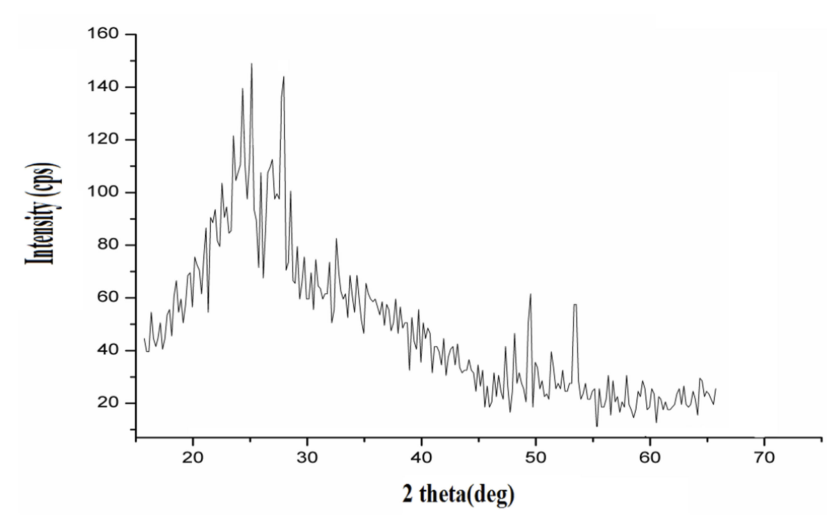

Figure 5 XRD spectra of synthesized ORMOSIL nanoparticles.

\section{Entrapment Efficiency}

Quercetin was loaded in core of ORMOSIL nanoparticles. The entrapment efficiency within the nanoparticles was calculated as $88.38 \%$.

\section{In Vitro Release Kinetics}

The nanoparticles showed a slow and sustained quercetin release at the physiological $\mathrm{pH} 7.4$ in phosphate buffer. Around $80 \%$ of the drug was released from nanoparticles in $96 \mathrm{hrs}$ study (Figure 6).

\section{Effect Of Quercetin, Q-ORMOSIL And LA-Q- ORMOSIL On The Plasma Enzymes ALT, AST And ALP Activities}

Plasma ALT, AST and ALP activities increased significantly in cyclophosphamide-treated animals compared to the control group $(\mathrm{p}<0.05)$ (Figure 7). Whereas, treatment with bulk quercetin, Q-ORMOSIL, and LA-Q-ORMOSIL provided significant restoration of the plasma ALT activity compared to cyclophosphamide-treated rats (Figure 7A). In the case of AST, significant inhibition was noted in Q-ORMOSIL and LA-Q-ORMOSIL treated rats compared 


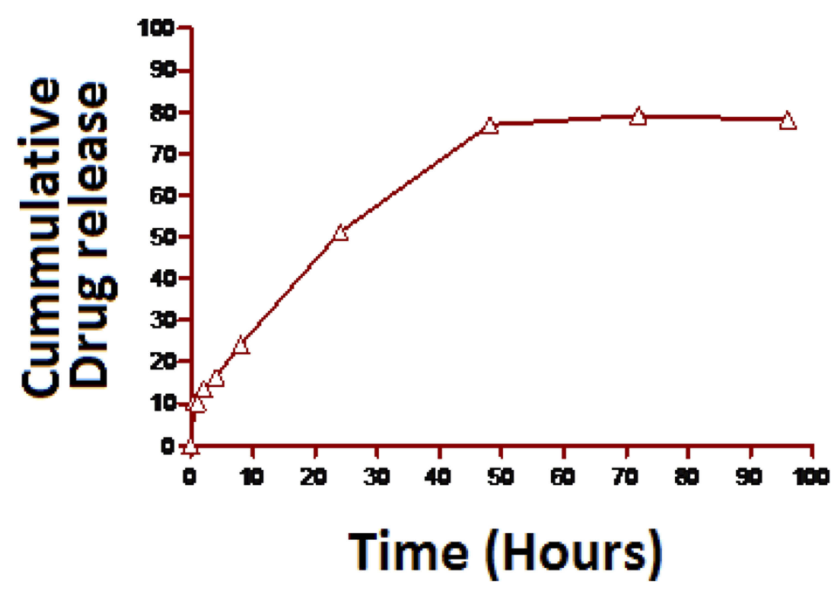

Figure 6 In vitro release study of nanoparticles.

to cyclophosphamide (Figure 7B). Additionally, a significant decrease in plasma AST activity was noted in LA-QORMOSIL group compared to bulk quercetin and Q-ORMOSIL treated group $(\mathrm{p}<0.05)$ (Figure $7 \mathrm{~B})$. Plasma ALP activity was also reduced significantly LA-Q-
ORMOSIL treatment compared to cyclophosphamide group $(\mathrm{p}<0.05)$ (Figure $7 \mathrm{C})$.

\section{Oxidative Stress Variable}

ROS level was significantly higher in the CP-treated group than the control group $(\mathrm{p}<0.05)$ (Figure 8$)$. Whereas, quercetin alone, Q-ORMOSIL and LA-Q-ORMOSIL treatments restored ROS level marginally. LA-Q-ORMOSIL treatment showed a significant reduction in ROS level compared to $\mathrm{CP}$ and $\mathrm{CP}+\mathrm{Q}$ treated group $(\mathrm{p}<0.05)$ (Figure $8 \mathrm{~A})$. Further, the elevated level of ROS also accompanied by an increased TBARS level. A significant increase in TBARS level was noted in the cyclophosphamide group compared to the control group (Figure 8B). There was a significant decrease in TBARS in quercetin alone, Q-ORMOSIL and LA-QORMOSIL treated groups compared to cyclophosphamide group (Figure 8B). LA-Q-ORMOSIL treated group showed a significant difference in the levels of TBARS compared to quercetin and Q-ORMOSIL groups (Figure 8B).

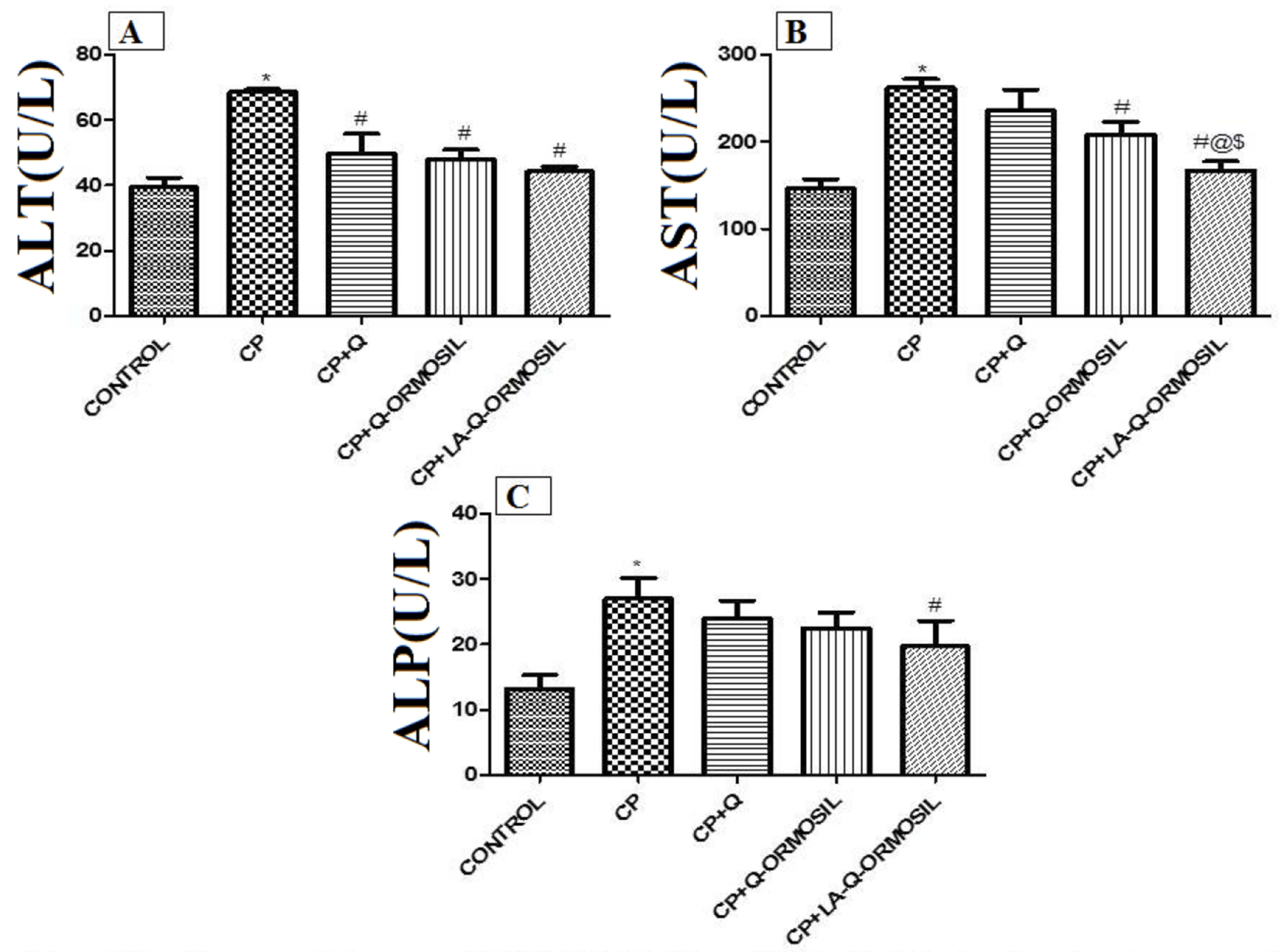

Figure 7 Results represented as mean \pm SD. (A) ALT, (B) AST, and (C) ALP. Statistical analysis done by one-way ANOVA followed by Bonferroni's test and results obtained are significantly different $(P<0.05$, * vs control group, \# vs CP group, @ vs CP + Q group and (\$) vs CP + Q-ORMOSIL nanoparticle). 

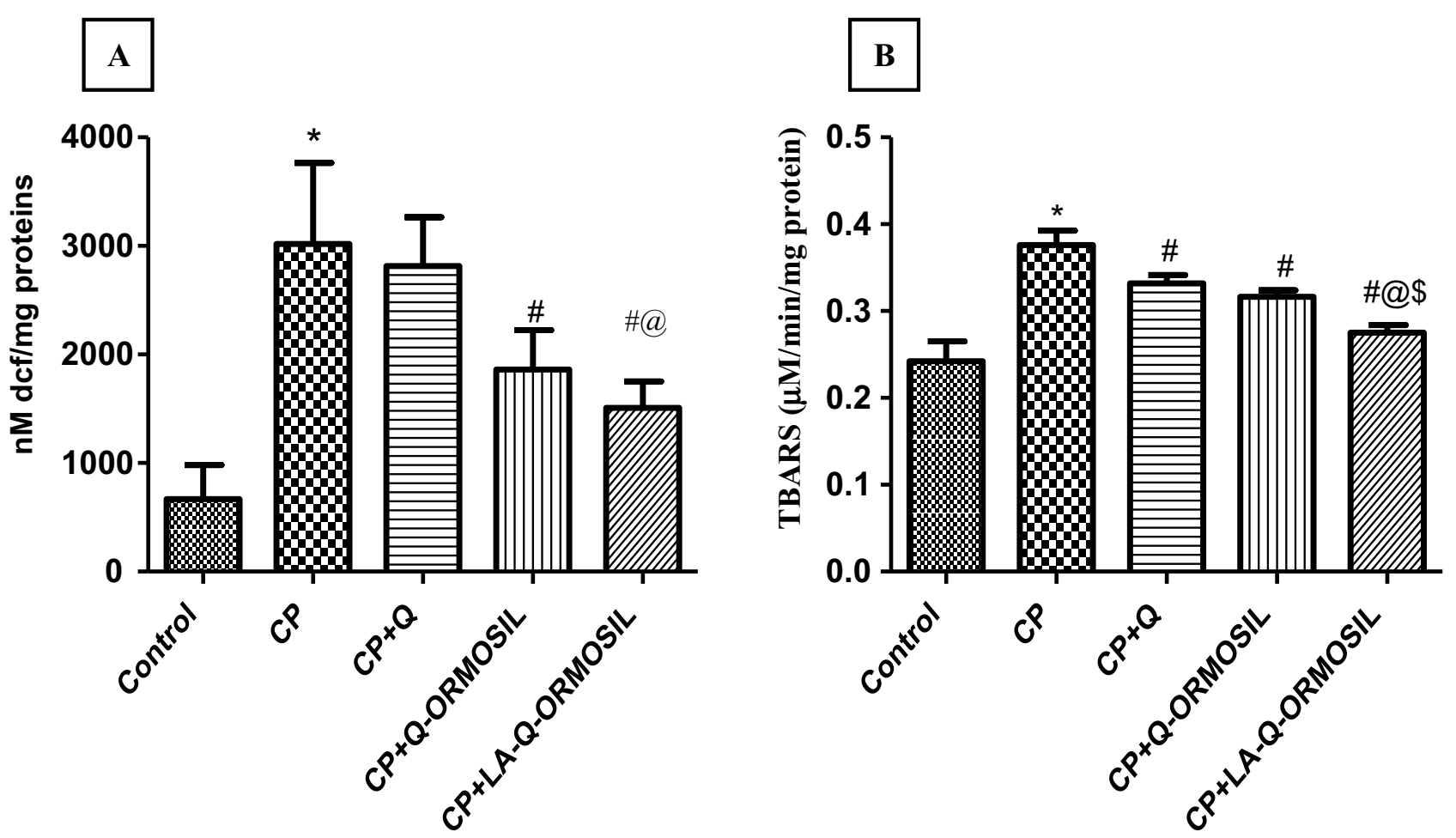

Figure 8 Results represented as mean \pm SD (A) ROS and (B) TBARS. Statistical analysis done by one-way ANOVA followed by Bonferroni's test and results obtained are significantly different ( $P<0.05$, * vs control group, \# vs CP group, @ vs CP + Q group and (\$) vs CP + Q-ORMOSIL nanoparticle).

Administration of CP led a decreased SOD activity in CP group compared to control $(\mathrm{p}<0.05)$ (Figure 9A) and treatment with nanoparticles showed a significant increase in SOD activity compared to CP group ( $<<0.05)$ (Figure 9A). The antioxidant level of catalase was significantly decreased in the cyclophosphamide group compared to control $(\mathrm{p}<0.05)$ (Figure 9B) while treatment with quercetin did not have any effect on catalase activity (Figure 9B). A significant increase in catalase activity was noted in Q-ORMOSIL and LA-Q-ORMOSIL treated group compared to cyclophosphamide groups ( $\mathrm{p}<0.05$ ) (Figure 9B) while, treatment with LAQ-ORMOSIL produced a significant recovery in catalase compared to quercetin $(\mathrm{p}<0.05)$ (Figure 9B).

GSH level was significantly decreased in the rats exposed to cyclophosphamide compared to controls $(p<0.05)$ (Figure 9C). A significant increase in the level of GSH was observed in quercetin, Q-ORMOSIL and LA-Q-ORMOSIL treatment groups compared to cyclophosphamide-treated group $(p<0.05)$ (Figure 9C). GST activity decreased in the CP-treated group $(p<0.05)$ compared to control (Figure 9D) while treatment with Q and Q-ORMOSIL showed an insignificant recovery in GST level. LA-Q-ORMOSIL provided a significant increase in GST activity compared to $\mathrm{CP}$ alone treated group $(\mathrm{p}<0.05)$ (Figure 9D).

\section{Histopathology}

Histopathological changes in processed liver sections were examined by the use of hematoxylin and eosin staining. As seen in Figure 10 (Panel A and B) stained section of the control group showed normal architecture of liver hepatocytes cells with no changes in its pathology, but in case of cyclophosphamide-treated group (Panel C and D) significant changes in cell structure, dilation, and congestion of central vein, sinusoids dilation, presence of neutrophil infiltration around the cells, ballooning and vacuolization of hepatocytes in CP-treated rats and also the presence of binucleated hepatocytes in them were seen. In the quercetin group (Panel E and F) absence of dilation and congestion of central vein and sinusoids dilation but ballooning and vacuolization of cells were seen. Treatment with Q-ORMOSIL (Panel $\mathrm{G}$ and $\mathrm{H}$ ) decreased dilation and congestion of cells and reduction in neutrophil infiltration were observed while in case of LA-Q-ORMOSIL (Panel I and J) marked improvement in liver cells were noted and the normal architecture of liver tissue was restored.

\section{Discussion}

Nanomedicine plays an important role in the therapeutics and targeted drug delivery and has a cutting edge over the 

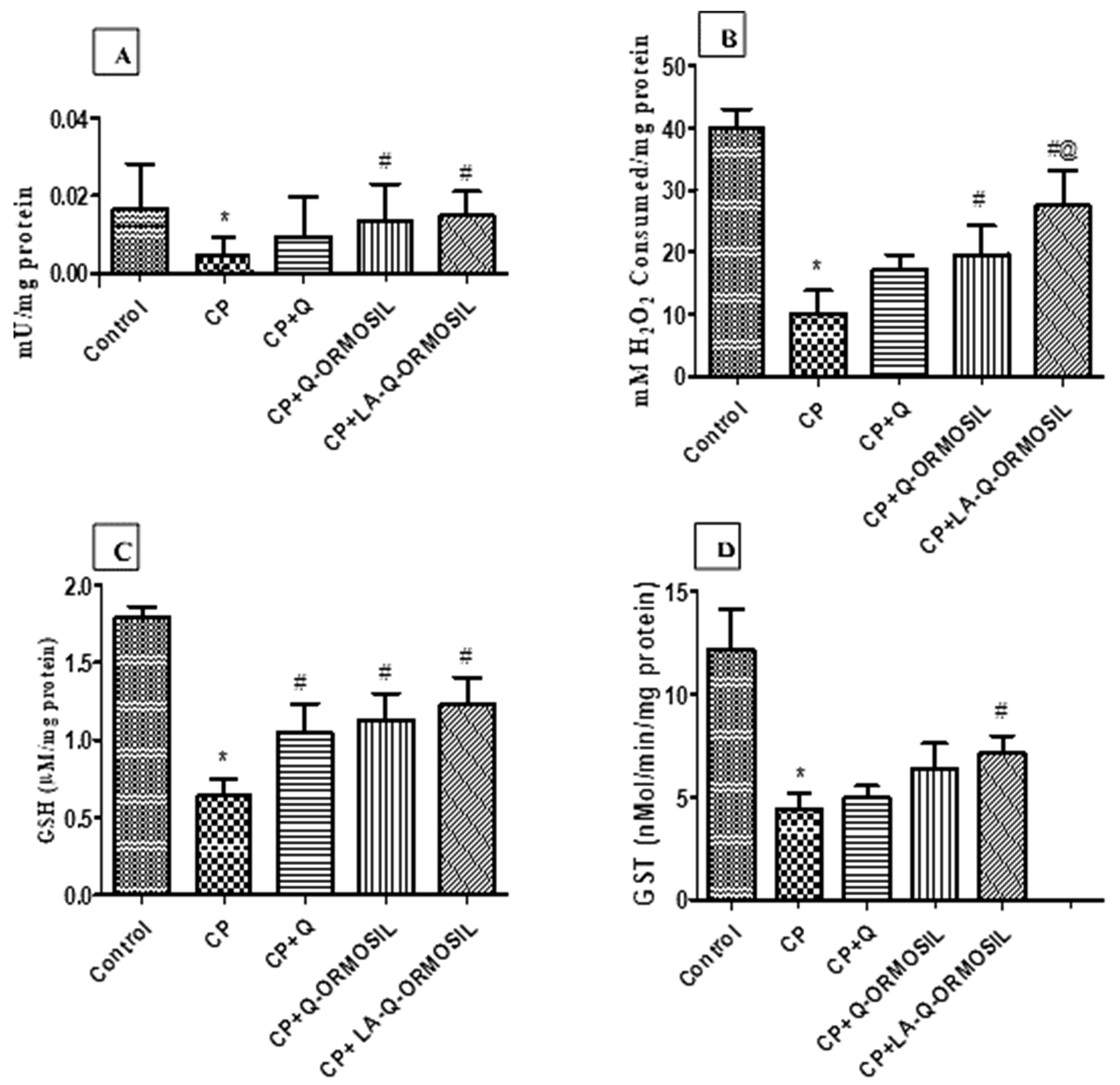

Figure 9 Results represented as mean \pm SD. Where (A) SOD, (B) catalase, (C) GSH, and (D) GST. Statistical analysis done by one-way ANOVA followed by Bonferroni's test and results obtained are significantly different $(P<0.05$, * vs control group, \# vs CP group, @ vs CP + Q group and (\$) vs CP + Q-ORMOSIL nanoparticle).

conventional methods of drug delivery. In the current study, we synthesized monodispersed, spherical targeted LA-Q-ORMOSIL nanoparticles for the delivery quercetin, an effective antioxidant. Figure 1 provides a schematic overview of nanoparticle preparation, characterization and its in vivo study. The potential of quercetin as an effective and potent antioxidant is well known. ${ }^{30,31} \mathrm{We}$ in the current provide data where we report the efficacy of LA conjugated ORMOSIL nanoparticles against CPinduced hepatotoxicity. In targeted drug delivery, selective transportation of drug to targeted tissues, organs, and cells through a variety of drug carrier attached with their respective receptors on the cell surface can be achieved successfully. ${ }^{32}$ We added an organic group i.e amine, to the synthesized silica nanoparticles which imparts them a certain degree of flexibility to the rigid silica matrix, and leads to enhanced stability of silica nanoparticles against flocculation/precipitation in aqueous systems. Besides, a targeted moiety i.e. lactobionic acid(LA) is easily conjugated in the organic arm of ORMOSIL nanoparticle's 


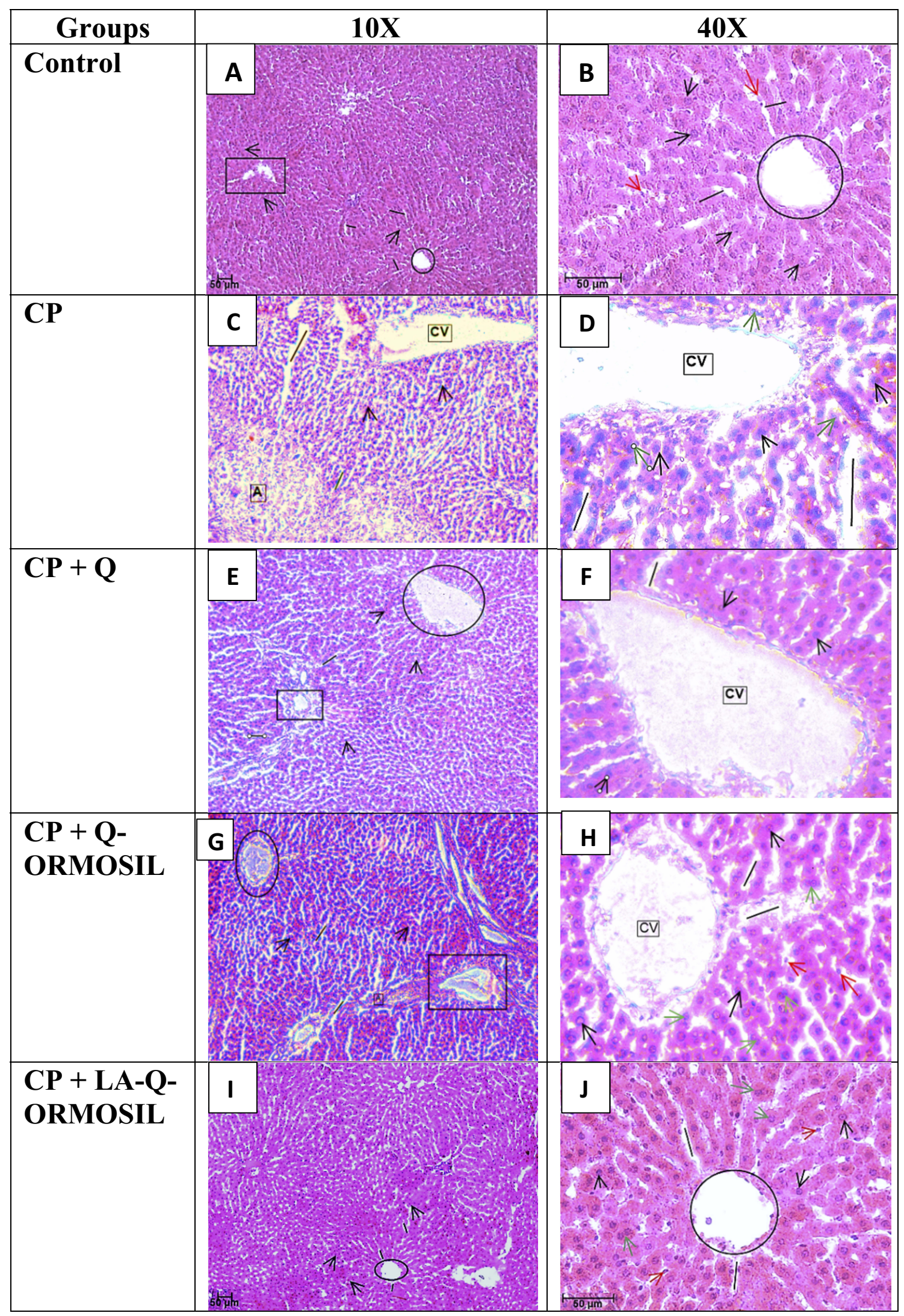

Figure 10 Rat liver histopathology (H\&E) from: (A and B) control showing normal architecture of liver cells; (C and D) cyclophosphamide showing dilation and congestion of central vein and sinusoids, neutrophil infiltration, vacuolization of hepatocytes and presence of binucleated hepatocytes; $(\mathbf{E}$ and $\mathbf{F}) \mathrm{CP}+\mathrm{Q}$ shows dilation and congestion of central vein and sinusoids; (G-J) CP+ Q-ORMOSIL and CP+ LA-Q-ORMOSIL shows marked improvement in liver cells. 
surface. We thus recommend the use of such kind of modification in future studies which might open the opportunity for further fabrication with other diagnostic/therapeutic/bio-targeting agents and makes them amenable as "multimodal" nanoparticles.

Quercetin helps in the protection against ROS generated by toxicants. It has been reported in earlier studies that quercetin is effective in protecting the liver from injuries. ${ }^{32-34}$ Thus we planned to investigate the protective value of quercetin against $\mathrm{CP}$ induced liver injury when it is encapsulated in an ORMOSIL nanocarrier and administered at a very low dose (1000 times lower than bulk quercetin dose). In our study, quercetin alone, Q-ORMOSIL and LA-Q-ORMOSIL nanoparticles were used as treatment regimens, while nanoparticles were prepared to increase the bioavailability and solubility of quercetin in the system. The study demonstrated that quercetin loaded ORMOSIL nanoparticles provided significant hepatoprotection compared with quercetin alone against CP. Q-IRMOSIL was further conjugated with lactobionic acid (LA) using coupling reaction, where LA is a glycosylated moiety and a well-known ligand for the asialoglycoprotein receptor (ASGPR) on the hepatocyte surface. Targeted delivery for quercetin improved its solubility and bioavailability in hepatocytes cells to provide hepatoprotection at 1000 times low dose level i.e. $50 \mu \mathrm{g} / \mathrm{kg} /$ day compared to bulk quercetin i.e. $50 \mathrm{mg} / \mathrm{kg} /$ day alone. Our conclusion is supported by the data from this study particularly various blood parameters, biochemical (including oxidative stress) and histopathological studies.

Synthesis of ORMOSIL nanoparticles was carried as reported in literature where nanomicellar solution was turned into the yellowish-orange color on the addition of drug quercetin, whereas in void nanoparticles, a white color solution appeared. Presence of quercetin in nanoparticle was confirmed by UV- visible spectroscopy where quercetin and quercetin loaded nanoparticles shows its absorbance peak at a wavelength of $402 \mathrm{~nm}$. In the case of void nanoparticles, no peak was observed at a wavelength of $402 \mathrm{~nm}$. The characteristic peak of quercetin at $402 \mathrm{~nm}$ confirmed that drug was successfully loaded inside the reverse micellar core of ORMOSIL nanoparticles.

FT-IR spectroscopy was performed to determine the presence of surface and functional groups and the interaction of the functional group with drug moiety. Peaks observed at $3375 \mathrm{~cm}^{-1}, 3294 \mathrm{~cm}^{-1}, 1362 \mathrm{~cm}^{-1}$ and $2928 \mathrm{~cm}^{-1}$ were characteristic peak for quercetin. Whereas, in the case of Q-ORMOSIL nanoparticles, these peaks were not observed which indicated that there was some modification occur between quercetin and silica nanoparticle due to which these peaks disappeared and confirmed the laoding of quercetin inside the nanoparticles. Surface modification of Q-ORMOSIL with LA also confirmed by FTIR spectroscopy. Amide bond formation takes place between a carboxylic group of lactobionic acid (activated by EDC and NHS) with the amine group of Q-ORMOSIL nanoparticle to form a stable product. It was confirmed by detecting peak at $3284 \mathrm{~cm}^{-1}$ which represents $\mathrm{NH}_{2}$ vibration with increased absorption and $1636 \mathrm{~cm}^{-1}$ represents $\mathrm{N}-\mathrm{H}$ bond formation having high intensity. All the obtained peaks confirm the successful conjugation of LA on the surface of Q-ORMOSIL and quercetin encapsulation in ORMOSIL nanoparticles.

Synthesized nanoparticles further characterized by TEM, DLS, XRD, and EDX. TEM used to determine size, shape, and morphology of nanoparticles. TEM image depicts that the average size of quercetin nanoparticles was around $80 \mathrm{~nm}$, and it was monodispersed with spherical morphology. DLS(dynamic light scattering) again confirmed the particle size distribution based on their intensity. The average size was found to be 103.5 $\mathrm{nm}$. The crystalline nature of formed silica nanoparticles was confirmed by X-ray diffraction analysis. From EDX analysis we further confirm the presence of silica in the formed nanoparticles. The entrapment efficiency of quercetin-loaded nanoparticles was around $88.83 \%$, it measures the percentage of drug that is successfully entrapped in the nanoparticle carrier. Our data indicated that ORMOSIL nanoparticles is a good carrier for entrapment and delivering hydrophobic drugs to a greater extent, ORMOSIL entraps a major amount of drug and prevent their degradation from the external cytosolic environment. Whereas, in vitro release study suggest that how much amount of drug is released in a particular period. The nanoparticles illustrate a slow and sustained quercetin release at the physiological $\mathrm{pH} 7.4$ in phosphate buffer. Around $80 \%$ of the drug is released from nanoparticles within $96 \mathrm{hrs}$ which further confirms that synthesized ORMOSIL nanoparticles encapsulated quercetin inside its core and releases the drug in a sustained manner.

Plasma level of ALT, ALP, and AST enzymes is a marker for the assessment of the liver injury. ${ }^{35}$ Cyclophosphamide administration generates free radicals and oxidizes the fatty acids in cytoplasmic membrane phospholipids, which changes membrane morphology and function. These changes primarily increase the 
activities of ALT, ALP, and AST in blood. ${ }^{36,37}$ It was previously reported that quercetin decreases the level of these enzymes. ${ }^{38}$ Restoration of these enzymes activities in cyclophosphamide-induced liver injury group by quercetin might be due to its membrane-stabilizing activity. The similar results were observed in the present study, where we observed a significant increase in ALT, AST and ALP activities in CP administered animals (Figure 7). Treatment with quercetin alone, Q-ORMOSIL and LA-Q-ORMOSIL significantly restored these changes in the plasma. However, a more pronounced increase in the biomarkers of liver plasma levels was noted following treatment with LA-Q-ORMOSIL nanoparticles (Figure 7).

Reactive free radicals and oxidants result in cells and tissues damage. ${ }^{39}$ Stress generated through the use of chemotherapeutics may lead to various toxic effect. ${ }^{40}$ Oxidative stress induced by $\mathrm{CP}$ in the liver results in hepatotoxicity. ${ }^{3}$ Determination of ROS, TBARS, and antioxidant enzyme level in liver tissues are an early indicator of oxidative stress. ${ }^{41}$ Administration of cyclophosphamide elevates reactive oxygen species inside the cells due to the presence of its toxic metabolites which may lead cell injury. ${ }^{42}$ It was previously reported that quercetin decreased the level of reactive oxygen species by its free radicals scavenging action. ${ }^{43}$ We also observed a significantly higher level of ROS was significantly in CP-administered animals compared to normal controls (Figure 8A), which suggest that cyclophosphamide administration caused hepatic oxidative stress. On treatment with quercetin, Q-ORMOSIL and LA-Q-ORMOSIL a significant decrease in ROS level was observed (Figure 8A). Significant reduction in ROS was also seen in Q-ORMOSIL and LA-Q-ORMOSIL treated rats. On the other hand, a more significant reduction was seen in treatment with LA-Q-ORMOSIL nanoparticles (Figure 8A), which further confirms that LA-Q-ORMOSIL nanoparticles successfully delivered the drug on the targeted site.

TBARS levels indirectly indicate the level of lipid peroxidation and it was one of the manifestations of stress induced by the increased level of ROS, which linked with altered membrane structure and inactivation of enzymes. ${ }^{44}$ A significant increase in the TBARS level was seen in the case of CP-treated group compared to control (Figure 8B). Quercetin, Q-ORMOSIL, and LA-Q-ORMOSIL treatment were also effective in reducing the level of TBARS following co-adminsitration with CP. LA-Q-ORMOSIL treated group also showed a more significant reduction in the levels of TBARS compared to $\mathrm{CP}$, quercetin, and
Q-ORMOSIL treatment group (Figure 8B), which further confirms the more pronounced effects of targeted drug delivery.

Our data also showed that increased TBARS level is accompanied by a concomitant decrease in antioxidant enzyme activities like SOD, CATALASE, GSH, and GST. SOD prevents stress by converting cytotoxic superoxide radicals to $\mathrm{H}_{2} \mathrm{O}_{2}$ and oxygen molecule. Further catalase enzyme converts $\mathrm{H}_{2} \mathrm{O}_{2}$ into a water molecule. The Inadequate activity of catalase cannot degrade $\mathrm{H}_{2} \mathrm{O}_{2}$, and generate $\mathrm{OH}^{-}$radical which results in oxidative injury to liver cells. It has been reported that treatment with cyclophosphamide decreases antioxidant enzyme level. ${ }^{45}$ Quercetin increases antioxidant enzyme level by its antioxidant action where it reduces itself and prevents oxidation of other enzymes. ${ }^{46}$ In the present study, administration of CP showed decreased SOD activity whereas in the treated group there is the moderate recovery in SOD activity (Figure 9A). Catalase activity decreased significantly in $\mathrm{CP}$-administered group compared to the control however, treatment with quercetin showed an insignificant change in catalase activity. Treatment with Q-ORMOSIL and LA-Q-ORMOSIL significantly elevated the catalase activity (Figure 9B).

GSH is an antioxidant which on reduction protect against free radicals and other mediators. Similarly, catalase converts hydrogen peroxide molecule into water and oxygen molecule. ${ }^{47}$ GSH has reactive $-\mathrm{SH}$ group due to the presence of cysteine moiety. It works as a non-enzymatic antioxidant by an interaction between - $\mathrm{SH}$ group and ROS. It has been reported that metabolites of $\mathrm{CP}$ conjugates with GSH enzyme and depletes antioxidant level. ${ }^{48}$ In the present study, GSH level was significantly decreased in the rats administered with cyclophosphamide compared to controls (Figure 9C). Significant increase in the level of GSH was seen in animals treated with quercetin, Q-ORMOSIL, and LA-Q-ORMOSIL. More pronounced elevation of GSH level was observed noted in LA-Q-ORMOSIL nanoparticle treated group compared to other treatment groups (Figure 9C). GST prevent the cells against peroxidative damage and clear the metabolites of $\mathrm{CP}$ through enzymatic catalyzed conjugation reaction. ${ }^{45,49}$ In the present study, a significant decrease in GST activity in CP-adminisitered rats were seen compared to the control group (Figure 9D). Whereas, insignificant change was seen on treatment with quercetin and Q-ORMOSIL nanoparticles. Interestingly we noted a more pronounced increase in GST activity on 
treatment with LA-Q-ORMOSIL nanoparticles compared to other treatments (Figure 9D).

Literature suggests that cyclophosphamide causes liver injury by decreasing antioxidant level and increasing TBARS in injured tissues. ${ }^{50,51}$ Our result provides some interesting data suggesting that treatment with quercetin and nanoquercetin restored the level of antioxidants enzymes and also decreased ROS and TBARS levels in injured liver tissues compared to cyclophosphamide-administered animals. These results supported previous data obtained for the number of biomarkers in liver function enzymes in the treated and diseased group. The highlight of our study suggest a more pronounced beneficial effect of LA-Q-ORMOSIL nanoparticles compared to bulk quercetin treated animals. Our findings also suggest that at very low concentration, anti-oxidant drug quercetin exhibits effective therapeutic efficacy, which may be due to high encapsulation efficiency and targeted delivery of ORMOSIL nano-carrier.

Histopathological data confirms that cyclophosphamide disrupts the liver cell by causing dilation and congestion of central vein and sinusoids, CP also causes neutrophil infiltration around the cells along with vacuolization of hepatocytes. Presence of binucleated hepatocyte confirmed the liver injury induced by cyclophosphamide while, Quercetin loaded ORMOSIL nanoparticle's group treatment demonstrated improvement in the liver hepatocytes cells where we noted a reduced dilation and congestion of cells. Targeted drugloaded nanoparticle restored the normal architecture of hepatocytes. We thus conclude from the data that cyclophosphamide caused liver injury can be more effectively be reduced by the use of Quercetin loaded ORMOSIL nanoparticles compared to bulk quercetin.

\section{Conclusion}

Targeted nano-quercetin demonstrates a significant hepatoprotective effect compared with quercetin alone, against $\mathrm{CP}$-induced hepatotoxicity and considerably reduces the quercetin dose to many folds through alleviation of oxidative system. We also conclude that ORMOSIL nanoparticles increase the bioavailability of quercetin by targeted drug delivery to hepatocytes. Quercetin is known for its low bioavailability and thus on encapsulation of drug into nanocarrier, recommend that LA-QORMOSIL nanoparticles provide comparatively higher therapeutic efficacy in the protection against $\mathrm{CP}$-induced liver injury compared to quercetin alone. We propose that in future multifunctional dye-doped LA conjugated
quercetin-ORMOSIL nanoparticles could be used to facilitate nanoparticles uptake to hepatocytes for the liver diagnosis and treatment.

\section{Abbrevations}

ALT, Alanine Transaminase; AST, Aspartate Aminotra nsferase; ALP, Alkaline Phosphatase; GST, Glutathione -S transferase; TBARS, Thiobarbituric acid reactive substances; ROS, Reactive Oxygen species; TEM, Transmission electron microscopy; FTIR, Fourier transform infrared; EDX; Energy Dispersive X-Ray Analyzer; ANOVA, One-way analysis of variance; $\mathrm{CP}$, Cyclophosphamide; DMF, Dimethylformamide; EDC, 1-ethyl-3-(3-dimethylaminopropyl) carbodiimide; LA, Lactobionic acid; LA-Q-ORMOSIL, Lactobionic acid conjugated quercetin loaded organically modified silica nanoparticles; NHS, N-hydroxysuccinimide; ORMOSIL, Organically modified silica nanoparticles; Q, Quercetin; Q-ORMOSIL, Quercetin loaded Organically modified silica nanoparticles

\section{Acknowledgment}

The authors thank the Department of Pharmaceuticals, Ministry of Chemical and Fertilizes, Govt. of India for their support and acknowledge the award of Women Scientist Scheme (WOS-A), Department of Science and Technology, Government of India (grant no. SR/WOS-A/ LS-1224/2015 to SN). Communication number is NIPER$\mathrm{R} /$ Communication/090.

\section{Disclosure}

The authors report no conflicts of interest in this work.

\section{References}

1. Rehman MU, Tahir M, Ali F, et al. Cyclophosphamide-induced nephrotoxicity, genotoxicity, and damage in kidney genomic DNA of Swiss albino mice: the protective effect of Ellagic acid. Mol Cell Biochem. 2012;365:119-127. doi:10.1007/s11010-012-1250-x

2. Haubitz M. Acute and long-term toxicity of cyclophosphamide. Transplantationsmedizin. 2007;19:26-31.

3. Zarei M, Shivanandappa T. Amelioration of cyclophosphamide-induced hepatotoxicity by the root extract of decalepis hamiltonii in mice. Food Chem Toxicol. 2013;57:179-184. doi:10.1016/j.fct.2013.03.028

4. Mohammad MK, Avila D, Zhang J, et al. Acrolein cytotoxicity in hepatocytes involves endoplasmic reticulum stress, mitochondrial dysfunction and oxidative stress. Toxicol Appl Pharmacol. 2012;265:7382. doi:10.1016/j.taap.2012.09.021

5. Adams JD, Klaidman LK. Acrolein-induced oxygen radical formation. Free Radic Biol Med. 1993;15:187-193. doi:10.1016/0891-5849(93) 90058-3

6. Kim YW, Ki SH, Lee JR, et al. Liquiritigenin, an aglycone of liquiritin in Glycyrrhizae radix, prevents acute liver injuries in rats induced by acetaminophen with or without buthionine sulfoximine. Chem Biol Interact. 2006;161:125-138. doi:10.1016/j.cbi.2006.03.008 
7. Wagoner J, Negash A, Kane OJ, et al. Multiple effects of silymarin on the hepatitis C virus lifecycle. Hepatology. 2010;51:1912-1921. doi: $10.1002 /$ hep. 23587

8. Manna P, Sinha M, Sil PC. Protection of arsenic-induced hepatic disorder by arjunolic acid. Basic Clin Pharmacol Toxicol. 2007;101:333-338. doi:10.1111/pto.2007.101.issue-5

9. Zhao X, Cong X, Zheng L, Xu L, Yin L, Peng J. Dioscin, a natural steroid saponin, shows remarkable protective effect against acetaminophen-induced liver damage in vitro and in vivo. Toxicol Lett. 2012;214:69-80. doi:10.1016/j.toxlet.2012.08.005

10. Erlund I. Review of the flavonoids quercetin, hesperetin, and naringenin. Dietary sources, bioactivities, bioavailability, and epidemiology. Nutr Res. 2004;24:851-874. doi:10.1016/j.nutres.2004.07.005

11. Erden Inal M, Kahraman A. The protective effect of flavonol quercetin against ultraviolet a induced oxidative stress in rats. Toxicology. 2000;154:21-29. doi:10.1016/S0300-483X(00)00268-7

12. Igura $\mathrm{K}$, Ohta T, Kuroda $\mathrm{Y}$, Kaji K. Resveratrol and quercetin inhibit angiogenesis in vitro. Cancer Lett. 2001;171:11-16. doi:10.1016/ S0304-3835(01)00443-8

13. Yang K, Lamprecht SA, Liu Y, et al. Chemoprevention studies of the flavonoids quercetin and rutin in normal and azoxymethane-treated mouse colon. Carcinogenesis. 2000;21:1655-1660. doi:10.1093/car$\operatorname{cin} / 21.9 .1655$

14. Sorata Y, Takahama U, Kimura M. Protective effect of quercetin and rutin on photosensitized lysis of human erythrocytes in the presence of hematoporphyrin. Biochim Biophys Acta Gen Subj. 1984;799:313317. doi:10.1016/0304-4165(84)90276-9

15. Bona S, Filippin LI, Di Naso FC, et al. Effect of antioxidant treatment on fibrogenesis in rats with carbon tetrachloride-induced cirrhosis. ISRN Gastroenterol. 2012;2012:1-7. doi:10.5402/2012/762920

16. Chen X, Yin OQP, Zuo Z, Chow MSS. Pharmacokinetics and modeling of quercetin and metabolites. Pharm Res. 2005;22:892-901. doi:10.1007/s11095-005-4584-1

17. Harwood M, Danielewska B, Borzelleca JF, Flamm GW, Williams GM, Lines TC. A critical review of the data related to the safety of quercetin and lack of evidence of in vivo toxicity, including lack of genotoxic/carcinogenic properties. Food Chem Toxicol. 2007;45:2179-2205. doi:10.1016/j.fct.2007.05.015

18. Justino GC, Santos MR, Canário S, Borges C, Florêncio MH, Mira L. Plasma quercetin metabolites: structure-antioxidant activity relationships. Arch Biochem Biophys. 2004;432:109-121. doi:10.1016/j. abb.2004.09.007

19. Kumar R, Roy I, Ohulchanskyy TY, et al. Covalently dye-linked, surface-controlled, and bioconjugated organically modified silica nanoparticles as targeted probes for optical imaging. ACS Nano. 2008;2:449-456. doi:10.1021/nn700370b

20. Liu H, Wang H, Xu Y, et al. Lactobionic acid-modified dendrimerentrapped gold nanoparticles for targeted computed tomography imaging of human hepatocellular carcinoma. ACS Appl Mater Interfaces. 2014;6:6944-6953. doi:10.1021/am500761x

21. Maitra A, Dinda AK, Prashant CK, Naqvi S, Unnithan J, Samim M. Curcumin loaded organically modified silica (ORMOSIL) nanoparticle; a novel agent for cancer therapy. Int J Nanotechnol. 2012;9:862871. doi:10.1504/IJNT.2012.049451

22. Chen G, Li D, Li J, et al. Targeted doxorubicin delivery to hepatocarcinoma cells by lactobionic acid-modified laponite nanodisks. New J Chem. 2015;39:2847-2855. doi:10.1039/C4NJ01916D

23. Lowry OH, Rosebrough NJ, Farr AL, Randall RJ. Protein measurement with the Folin phenol reagent. J Biol Chem. 1951;193:265-275.

24. Dwivedi DK, Jena GB. Glibenclamide protects against thioacetamideinduced hepatic damage in Wistar rat: investigation on NLRP3, MMP2, and stellate cell activation. Naunyn Schmiedebergs Arch Pharmacol. 2018;391:1257-1274. doi:10.1007/s00210-018-1540-2

25. Ohkawa H, Ohishi N, Yagi K. Assay for lipid peroxides in animal tissues by thiobarbituric acid reaction. Anal Biochem. 1979;95:351358. doi:10.1016/0003-2697(79)90738-3
26. Kakkar P, Das B, Viswanathan PN. A modified spectrophotometric assay of superoxide dismutase. Indian $J$ Biochem Biophys. 1984;21:130-132.

27. Sinha AK. Colorimetric assay of catalase. Anal Biochem. 1972;47:389-394. doi:10.1016/0003-2697(72)90132-7

28. Hissin PJ, Hilf R. A fluorometric method for determination of oxidized and reduced glutathione in tissues. Anal Biochem. 1976;74:214-226. doi:10.1016/0003-2697(76)90326-2

29. Habig WH, Michael J, Pabst WBJ. The first enzymetic step in mercapturic acid formation. J Biol Chem. 1974;249:7130-7140.

30. Sherif IO. The effect of natural antioxidants in cyclophosphamideinduced hepatotoxicity: role of $\mathrm{Nrf} / \mathrm{HO}-1$ pathway. Int Immunopharmacol. 2018;61:29-36. doi:10.1016/j.intimp.2018.05.007

31. Olayinka ET, Ore A, Ola OS, Adeyemo OA. Protective effect of quercetin on melphalan-induced oxidative stress and impaired renal and hepatic functions in rat. Chemother Res Pract. 2014;2014:1-8. doi: $10.1155 / 2014 / 936526$

32. Verma SK, Rastogi S, Arora I, Javed K, Akhtar M, Samim M. Nanoparticle based delivery of quercetin for the treatment of carbon tetrachloride mediated liver cirrhosis in rats. J Biomed Nanotechnol. 2016;12:274-285. doi:10.1166/jbn.2016.2153

33. Ashkani S, Bagheri F, Azarpira N, et al. Protective effects of quercetin on thioacetamide-induced acute liver damage and its related biochemical and pathological alterations. Egypt J Intern Med. 2017;28:123.

34. Chen X. Protective effects of quercetin on liver injury induced by ethanol. Pharmacogn Mag. 2010;6:135. doi:10.4103/0973-1296.62900

35. Lakshmi T, Sri Renukadevi B, Senthilkumar S, et al. Seed and bark extracts of Acacia catechu protects liver from acetaminophen induced hepatotoxicity by modulating oxidative stress, antioxidant enzymes and liver function enzymes in Wistar rat model. Biomed Pharmacother. 2018;108:838-844. doi:10.1016/j.biopha.2018.08.077

36. Zhai X, Zhang Z, Liu W, et al. Protective effect of ALDH2 against cyclophosphamide-induced acute hepatotoxicity via attenuating oxidative stress and reactive aldehydes. Biochem Biophys Res Commun. 2018;499:93-98. doi:10.1016/j.bbrc.2018.03.041

37. Sreelatha S, Padma PR, Umadevi M. Protective effects of Coriandrum sativum extracts on carbon tetrachloride-induced hepatotoxicity in rats. Food Chem Toxicol. 2009;47:702-708. doi:10.1016/j.fct.2008.12.022

38. Kabirifar R, Ghoreshi ZA, Safari F, Karimollah A, Moradi A, Eskandari-nasab E. Quercetin protects liver injury induced by bile duct ligation via attenuation of Rac1 and NADPH oxidase1 expression in rats. Hepatobiliary Pancreat Dis Int. 2017;16:88-95. doi:10.1016/S1499-3872(16)60164-9

39. Ezhilarasan D. Oxidative stress is bane in chronic liver diseases: clinical and experimental perspective. Arab $J$ Gastroenterol. 2018;19:56-64. doi:10.1016/j.ajg.2018.03.002

40. Raghu R, Karthikeyan S. Zidovudine and isoniazid induced liver toxicity and oxidative stress: evaluation of mitigating properties of silibinin. Environ Toxicol Pharmacol. 2016;46:217-224. doi:10.1016/ j.etap.2016.07.014

41. Gutteridge JMC. Lipid peroxidation and antioxidants as biomarkers of tissue damage. Clin Chem. 1995;41:1819.

42. Basu A, Bhattacharjee A, Samanta A, Bhattacharya S. Prevention of cyclophosphamide-induced hepatotoxicity and genotoxicity: effect of an 1-cysteine based oxovanadium(IV) complex on oxidative stress and DNA damage. Environ Toxicol Pharmacol. 2015;40:747-757. doi:10.1016/j.etap.2015.08.035

43. Tzankova V, Aluani D, Kondeva-Burdina M, et al. Hepatoprotective and antioxidant activity of quercetin loaded chitosan/alginate particles in vitro and in vivo in a model of paracetamol-induced toxicity. Biomed Pharmacother. 2017;92:569-579. doi:10.1016/j.biopha.2017.05.008

44. Oyagbemi AA, Omobowale OT, Asenuga ER, Akinleye AS, Ogunsanwo RO, Saba AB. Cyclophosphamide-induced hepatotoxicity in wistar rats: the modulatory role of gallic acid as a hepatoprotective and chemopreventive phytochemical. Int J Prev Med. 2016;61:29-36. 
45. Singh C, Prakash C, Tiwari KN, Mishra SK, Kumar V. Premna integrifolia ameliorates cyclophosphamide-induced hepatotoxicity by modulation of oxidative stress and apoptosis. Biomed Pharmacother. 2018;107:634-643. doi:10.1016/j.biopha.2018.08.039

46. Lin SY, Wang YY, Chen WY, Chuang YH, Pan PH, Chen CJ. Beneficial effect of quercetin on cholestatic liver injury. $J$ Nutr Biochem. 2014;25:1183-1195. doi:10.1016/j.jnutbio.2014.06.003

47. Droge W. Free radicals in the physiological control of cell function. Physiol Rev. 2002;82:47-95. doi:10.1152/physrev.00018.2001

48. Chakraborty P, Roy SS, Basu A, Bhattacharya S. Sensitization of cancer cells to cyclophosphamide therapy by an organoselenium compound through ROS-mediated apoptosis. Biomed Pharmacother. 2016;84:1992-1999. doi:10.1016/j.biopha.2016.11.006
49. HA D, van Ommen B, van Bladeren PJ. Involvement of human glutathione s-transferase isoenzymes in the conjugation of cyclophosphamide metabolites with glutathione. Cancer Res. 1994;54:62156220 .

50. Tuorkey MJ. Therapeutic potential of nigella sativa oil against cyclophosphamide-induced DNA damage and hepatotoxicity. Nutr Cancer. 2017;69:498-504. doi:10.1080/01635581.2017.1285408

51. Mahmoud AM. Hesperidin protects against cyclophosphamideinduced hepatotoxicity by upregulation of PPAR $\gamma$ and abrogation of oxidative stress and inflammation. Can J Physiol Pharmacol. 2014;92:717-724. doi:10.1139/cjpp-2014-0204

\section{Publish your work in this journal}

The International Journal of Nanomedicine is an international, peerreviewed journal focusing on the application of nanotechnology in diagnostics, therapeutics, and drug delivery systems throughout the biomedical field. This journal is indexed on PubMed Central, MedLine, CAS, SciSearch ${ }^{\mathbb{R}}$, Current Contents ${ }^{\mathbb{R}} /$ Clinical Medicine,
Journal Citation Reports/Science Edition, EMBase, Scopus and the Elsevier Bibliographic databases. The manuscript management system is completely online and includes a very quick and fair peer-review system, which is all easy to use. Visit http://www.dovepress.com/ testimonials.php to read real quotes from published authors. 